\title{
ANALYSIS OF THE ISP-50 DIRECT VESSEL INJECTION SBLOCA IN THE ATLAS FACILITY WITH THE RELAP5/MOD3.3 CODE
}

\author{
MEDHAT SHARABI* and JORDI FREIXA \\ Paul Scherrer Institut, Nuclear Energy and Safety Department \\ CH-5232 Villigen PSI, Switzerland \\ *Corresponding author. E-mail : medhat.sharabi@psi.ch
}

Received May 08, 2012

The pressurized water reactor APR1400 adopts DVI (Direct Vessel Injection) for the emergency cooling water in the upper downcomer annulus. The International Standard Problem number 50 (ISP-50) was launched with the aim to investigate thermal hydraulic phenomena during a 50\% DVI line break scenario with best estimate codes making use of the experimental data available from the ATLAS facility located at KAERI. The present work describes the calculation results obtained for the ISP-50 using the RELAP5/MOD3.3 system code. The work aims at validation and assessment of the code to reproduce the observed phenomena and investigate about its limitations to predict complicated mixing phenomena between the subcooled emergency cooling water and the two-phase flow in the downcomer. The obtained results show that the overall trends of the main test variables are well reproduced by the calculations. In particular, the pressure in the primary system show excellent agreement with the experiment. The loop seal clearance phenomenon was observed in the calculation and it was found to have an important influence on the transient progression. Moreover, the collapsed water levels in the core are accurately reproduced in the simulations. However, the drop in the downcomer level before the activation of the DVI from safety injection tanks was underestimated due to multi-dimensional phenomena in the downcomer that are not properly captured by one-dimensional simulations.

KEYWORDS : Small Break LOCA, ATLAS, Loop Seal Clearance, APR1400, RELAP5/MOD3.3, Direct Vessel Injection

\section{INTRODUCTION}

The Advanced Power Reactor (APR1400) is an evolutionary Pressurized Water Reactor (PWR) developed by the Korean nuclear industry as the next generation nuclear reactor in Korea and is being marketed worldwide as well. It is conceived to be based on the experience and the proven technology of the previous, standard Korean nuclear power plant; the Optimized Power Reactor (OPR1000). The first of this reactor - Shin-Kori3 \& 4 - is under construction and is foreseen to be in operation by 2013. The APR1400 has higher safety margins and larger component sizes to increase heat transfer, compared to the older design, for the envisaged power output. In addition, it has high seismic robustness and enhanced safety performance. Also, improved safety design features are introduced; in particular, adoptions of Direct Vessel Injection (DVI) for Safety Injection Tanks (SIT) to the upper downcomer nozzles ( $2.1 \mathrm{~m}$ above the cold legs) of the reactor pressure vessel rather than the conventional cold leg injection system [1].

The new thermal-hydraulics test loop ATLAS (Advanced Thermal-hydraulic test Loop for Accident Simulation) has been built at KAERI for the purposes of simu- lating a broad range of different design basis accidents and transient scenarios relevant to the safe operation of OPR1000 and APR1400 [2]. The facility provides high pressure experimental data for safety analysis and code validation for Large Break Loss of Coolant Accidents (LBLOCA), Small Break LOCA (SBLOCA), main steam line break, and steam generator tube rupture [2-4].

Since the DVI lines are also prone to break accidents, safety analysis studies for this scenario are required to ensure that the cladding heat up remains below the specified accepting criterion during the accident. The thermalhydraulic phenomena taking place in the downcomer during DVI line break accident were studied in previous work using an air-water separate effect experiment [5]. Later, a small-scale integral loop test facility, SNUF (Seoul National University Facility) was used to study the DVI line break transient by [6]. The facility employs steamwater as a working fluid and it was designed using a reduced height and a reduced pressure with appropriate scaling methods to reasonably simulate the APR1400. The phenomenon of the downcomer seal clearing was 
found to play an important role during a postulated accident in APR1400 for core uncover and integrity of the fuel. KAERI conducted a series of full scale pressure simulation experimental campaigns in the ATLAS facility for different break sizes of DVI line breaks [7]. In particular, the $50 \%$ DVI line break was approved by NEA/CSNI in 2008 for an International Standard Problem (ISP-50) for its importance to help in understanding the behavior of nuclear reactor system with the DVI line break scenario and to use this data for evaluation and assessment of the currently used best estimate thermal-hydraulic system codes. The $50 \%$ (corresponding to 6 inch in the prototype plant) DVI line break represents the limiting case where core uncover should be prevented with the prediction of the best estimate codes according to the recommendations by the Electrical Power Research Institute (EPRI) [8].

In the present work, the thermal-hydraulic system code RELAP5/MOD3.3 [9] is used for the analysis of ISP-50. Validation of the experimental data and assessment of code capabilities to reproduce correctly the observed phenomena is presented. This is necessary to investigate about possible code limitations to predict the complicated phenomena in the downcomer; arising from countercurrent flows of the vapor and the emergency cooling water directing downwards, and its influence on the overall test parameter predictions.

\section{EXPERIMENTAL FACILITY AND TEST CONDITIONS}

The ATLAS test facility is a full scale pressure, integral test loop designed to simulate the APR1400. It is a half length and $1 / 288$ volume, with respect to the prototype plant, scaled according to the methodology introduced by [10]. The scaling factors for diameters, flow rate, power and time are $1 / 12,1 / 203.6,1 / 203.6$ and $1 / \sqrt{2}$, respectively. Schematic plot of the geometrical configuration of the ATLAS facility is shown in Fig. 1. The facility has two loops comprising four cold legs and two hot legs as in the original prototype plant. The pressurizer is connected to the hot leg of the second loop and four Reactor Coolant Pumps (RCP) are incoporated to circulate the flow throughout the primary loop. Two steam generators are installed to condense the steam in direct condensers type design and then the condensate is turned back to the steam generators.

Four safety injection tanks are available to supply the Emergency Core Cooling (ECC) water to the upper downcomer. In addition, two Safety Injection Pumps (SIP) provide the high pressure long term cooling from the Refueling Water Tank (RWT). The facility includes different break lines connected to a tank that collects the break flow and simulates the reactor containment by keeping a specific back pressure. The break line is equipped with a quick opening valve and a break nozzle as well as instruments for measurements of pressure and temperature upstream and downstream of the break valve. The core is represented by 390 heated rods (having the same diameter as in the prototype plant), six unheated rods and five core guide tubes, in addition to nine spacer grids. The heated rods are divided into three groups and they can be controlled separately to obtain non-uniform radial distribution of the power. More details about the ATLAS facility can be found in the facility description report [8].

The test chosen for the ISP-50 starts with the opening of the break valve which is located at the DVI-4 line. The other three intact DVI lines can supply the ECC water into the upper downcower. In addition, only one high pressure SIP is available for the long term cooling assuming loss of off-site power to the diesel generator powering the other one. The SIT injection can operate in two different modes; one for the high flow rate and the other for the low flow rate to mimic the operation of the fluidic device equipped in the SIT of APR1400. Transition from the high to the low flow rate conditions is determined by the water level in each of the SITs; when it falls below a predefined set point the stem position of the flow control valves changes from full opening to a lower position. The core power is controlled to have a uniform radial distribution and the axial power is given by the chopped cosine profile. The total power generated is $8 \%$ of the scaled power of APR1400 and also the primary loop flow rate is reduced to $8 \%$ to have the same coolant temperature distribution as in the prototype plant. To account for the heat losses to the surrounding, the total scaled power which was used in the test is increased by an amount equivalent to the losses from the primary system. After the scram signal, the core power starts to decay following the ANS73 decay curve [11].

\section{MODEL NODALIZATION}

The results reported in this work for ISP-50 are obtained using RELAP5/MOD3.3 code [9]. The nodal-ization is based on the input deck prepared by the organizing institute (KAERI) for steady state operation of the ATLAS facility in addition to its original drawings information. Similar nodalization practices are typically used for accident analysis of APR1400 [6].

Figure 2 shows the details of the RELAP5 model nodalization comprising one-dimensional thermalhydraulic components to model different parts in the primary and secondary loops of the ATLAS facility. The core is divided into three parallel channels: the average core composed of 20 axial nodes, the hot channel and the guide tube. Only one group of heated rods is considered because the radial distribution of heat generation is uniform. The downcomer region is modeled with the annulus component and is divided uniformly in the azimuthal direction (i.e. two-dimensional representation) into six sections connected with each other by cross junctions to model more realistically multi-dimensional effects resulting 
from mixing in the downcomer. The bypass flows between the downcomer and the hot legs are modeled using pipe components connecting them at the prescribed locations. The friction losses and flow area are adjusted to satisfy the bypass flow in steady state conditions as in the experiment.
The break nozzle is modeled as a junction component with the abrupt area change option. The orifice flow area is $50 \%$ of the SIT line diameter. The break line is connected then to a time-dependent volume which represents the containment tank simulator. The back pressure in the

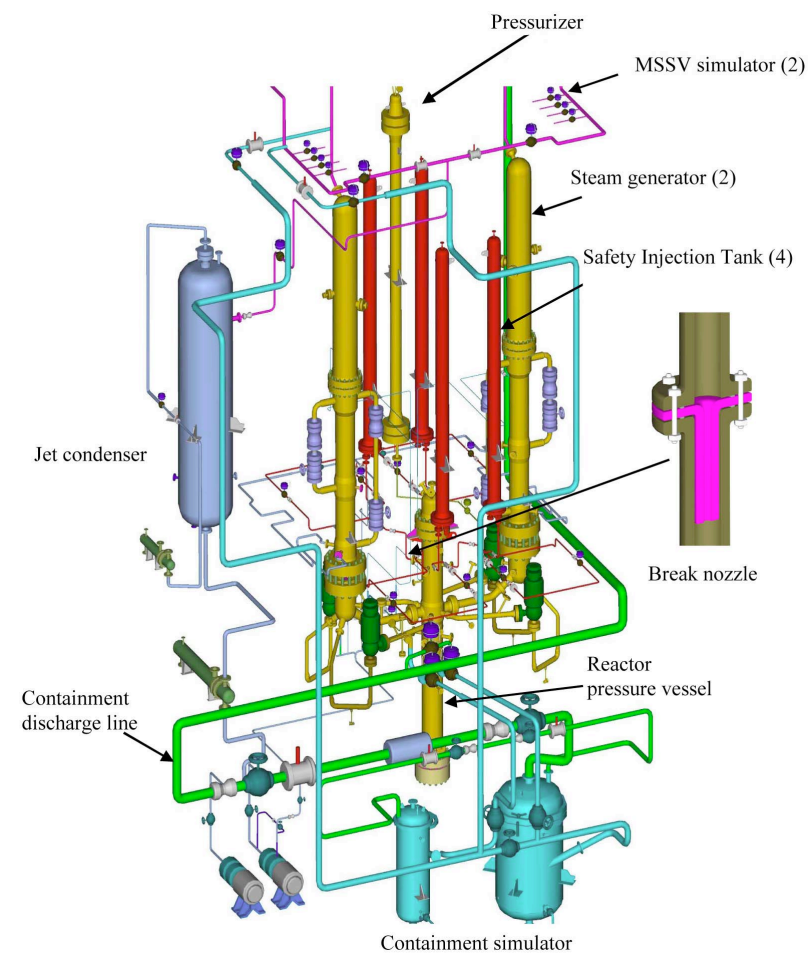

Fig. 1. Sketch of the ATLAS Integral Test Facility [2].

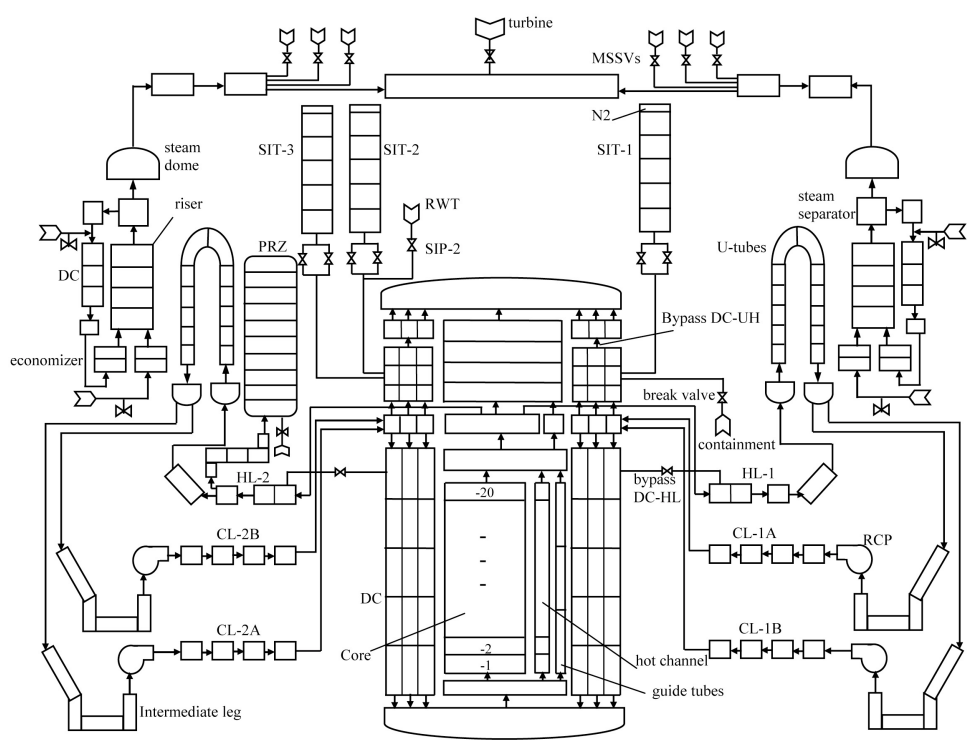

Fig. 2. RELAP5 Nodalization of the 50\% DVI Line Break in the ATLAS Facility 
containment is taken variable with time from the experimental data, though it does not affect the results because the break flow remained chocked during the transient due to the large pressure ratio. The simulations are conducted using the default RELAP5/MOD3.3 Henry-Fauske choked flow model [12]. The entrainment/pullthrough model is applied to the junction connecting the break line to the RPV. The Counter Current Flow Limiter (CCFL) model is activated at the core tie plate and the hot leg junction connecting its inclined section to the steam generator in each loop. The three intact SITs and their discharge lines are modeled with pipe components. The last control volume in each SIT has a different size than the others and it is initialized with Nitrogen gas. The level of water is set to 95\% in each SIT. The model for the operation of the fluidic device is accomplished using a trip valve and a control valve which changes the opening orifice size (to 18, 13 and $24 \%$ for SIT1, SIT2 and SIT3, respectively) if the level in the SIT falls below $72 \%$ of the SIT total height. The ECC water injected from the SIP is modeled using a time dependent junction connected to the RWT (modeled with a time-dependent volume) and the injected mass flow rate was parameterized as a function of the primary pressure. The secondary part of the steam generator is composed of riser, steam separator, downcomer, economizer and steam dome. The steam generator tube bundle is modeled with a single U-tube having an average height of the whole bundle. The turbine is modeled with a time-dependent volume component and set to the atmospheric pressure. Heat structures are included in the model to account for material heat capacities and for the heat losses to the environment.

The total number of volumes used to nodalize the facility is 309; the number of junctions is 305 and 80 heat structures are used to represent the heat transfer between different components. The time step was automatically chosen by the code and it was restricted by the Courant number throughout the transient calculations. The minimum time step used in the calculations is $3.6 \times 10^{-3} \mathrm{~s}$. The $\mathrm{CPU}$ time for a transient duration time of $3000 \mathrm{~s}$ was $3050 \mathrm{~s}$.

\section{RESULTS AND DISCUSSION}

\subsection{Steady-state Results}

The calculations are performed initially to reach the steady state conditions that match the initial conditions of the ISP-50 test. The steady state conditions are achieved after $10000 \mathrm{~s}$ starting from the initialized conditions set by the user. A comparison between the steady state conditions obtained from the RELAP5/MOD3.3 calculations and the experimental initial conditions are shown in Table 1 for the main test parameters in the primary, secondary, ECCS and the containment simulator. Reasonable agreements are obtained as indicated by the absolute per- centage error shown in the last column in the table. The largest difference seen in the table is for the primary loop flow rate with a value of $6.8 \%$ but it remains close to the relatively high uncertainty band of $\sim 5 \%$ for cold leg mass flow rate measurements. Therefore, this mass flow rate obtained from steady state calculations was adopted in order to instead have good agreements for the core outlet temperature. The mass flow rate through the primary side is fulfilled with low speeds of the RCPs of $\sim 23 \mathrm{rpm}$ in addition to the contribution from natural circulation. As seen in Fig. 2, water level control using artificial mass sources for pressurizer and steam generators are used for initializations purposes only to achieve the ISP-50 initial conditions and later on, the steady state conditions are kept without any regulations. The initial values for the ECCS are given in the test prescription and they are used in the calculations, so they do not show any discrepancies.

Heat losses are modeled in both the primary (applied to RPV and the connecting legs) and the secondary sides by assuming convective boundary conditions to the environment surroundings given an ambient air temperature of $298.15 \mathrm{~K}$. The heat transfer coefficients for the primary and secondary sides were varied separately in a series of calculations to match the experimentally measured heat losses under steady state conditions. The values finally used are 17 and $4.5 \mathrm{~W} / \mathrm{m}^{2} \mathrm{~K}$ for the primary and secondary sides, respectively. The initial total core power is then used in the calculations without subtraction of the primary system heat losses.

\subsection{ISP-50 Events Chronology of the Transient}

After the calculated steady state conditions are maintained constant for several minutes, the transient starts with the opening of the break line trip valve which opens within $0.5 \mathrm{~s}$. A comparison between the timing sequence of the main transient events in the ISP-50 predicted by RELAP5/MOD3.3 and that obtained from the experimental test is shown in Table 2. The calculated sequences show general good agreements with the experimental values. As seen in the table, most of the trips are governed by a Low Pressurizer Pressure (LPP) signal. So, successful prediction of the primary pressure during the transient leads to good estimation of the trip actions.

The first opening of the Main Steam Safety Valves (MSSV) takes place when the secondary pressure rises to 8.1 MPa. Similar open timings are observed in both steam generators and they occur with a delay of $3.6 \mathrm{~s}$ compared to the experiment for the first opening. The primary pressure encounters depressurization starting from an operating pressure of $15.53 \mathrm{MPa}$ and when the pressurizer pressure falls to $10.72 \mathrm{MPa}$, the LPP trip is activated at a time of 25 $\mathrm{s}$ similar to the measurement. As a consequence, pressurizer heater trip, RCP trip and mean feed water isolation are triggered with the actuation of the LPP signal, having different short delays of time as indicated in Table 2. The 
Table 1. Major Parameters at Steady State Conditions

\begin{tabular}{|c|c|c|c|}
\hline Variable & Experiment & Calculation & Difference \% \\
\hline \multicolumn{4}{|l|}{ Primary system } \\
\hline Core power, MW & 1.635 & 1.638 & 0.18 \\
\hline Pressure, $\mathrm{Pa}$ & $15.67 \times 10^{6}$ & $15.53 \times 10^{6}$ & 0.89 \\
\hline Core inlet temperature, $\mathrm{K}$ & 562.7 & 562.33 & 0.06 \\
\hline Core outlet temperature, $\mathrm{K}$ & 597.7 & 597.4 & 0.05 \\
\hline CL flow rate, $\mathrm{kg} / \mathrm{s}$ & $2.2 \pm 5 \%$ & 2.05 & 6.8 \\
\hline Bypass HL to DC flow rate, $\mathrm{kg} / \mathrm{s}$ & $\sim 0$ & 0 & 0 \\
\hline Bypass UH to DC flow rate, $\mathrm{kg} / \mathrm{s}$ & $\sim 0$ & -0.033 & $\sim 0.033$ \\
\hline PZR level, m & 3.362 & 3.3 & 1.7 \\
\hline $\mathrm{RCP}, \mathrm{rpm}$ & $15 \pm 5$ & 23 & $\sim 15$ \\
\hline \multicolumn{4}{|l|}{ Secondary System } \\
\hline Pressure, $\mathrm{Pa}$ & $7.83 \times 10^{6}$ & 7.86 & 0.38 \\
\hline Steam temperature, $\mathrm{K}$ & 566.2 & 566.9 & 0.01 \\
\hline FW temperature, $\mathrm{K}$ & 505.9 & 505.37 & 0.1 \\
\hline FW flow to SG economizer, $\mathrm{kg} / \mathrm{s}$ & $0.42 \sim 0.44$ & 0.42 & 0 \\
\hline FW flow to SG DC, $\mathrm{kg} / \mathrm{s}$ & $\sim 0$ & 0 & 0 \\
\hline SG level, m & $1.97 \sim 2.03$ & 2.1 & $\sim 3$ \\
\hline Heat removal per each SG, MW & 0.7537 & 0.7509 & 0.3 \\
\hline \multicolumn{4}{|l|}{ ECCS } \\
\hline SIT pressure, $\mathrm{MPa}$ & 4.19 & 4.19 & 0 \\
\hline SIT temperature, $\mathrm{K}$ & 323.5 & 323.5 & 0 \\
\hline SIT water level, $\%$ & $\sim 95$ & 95 & 0 \\
\hline RWT temperature, $\mathrm{K}$ & 321.3 & 321.3 & 0 \\
\hline \multicolumn{4}{|l|}{ Containment } \\
\hline Pressure, $\mathrm{Pa}$ & $10^{5}$ & $10^{5}$ & 0 \\
\hline
\end{tabular}

RCPs coastdown is started with the LPP signal; however its speed goes to zero $15 \mathrm{~s}$ later than in the experiment due to the influence by the moment of inertia of the rotating impeller. Afterwards, the core power follows the ANS exponential decay curve [11] multiplied by 1.2 at a calculated time of $26 \mathrm{~s}$. After a short period of time, the high pressure SIP-2 is triggered to inject cooling water at a temperature of $321.3 \mathrm{~K}$ in the DVI line at $54 \mathrm{~s}$. When the Lower Upper Downcomer Pressure (LUDP) falls to 4.03 $\mathrm{MPa}$, the three intact SITs are activated at $469 \mathrm{~s}$. The SITs are controlled to inject cooling water at high flow rate conditions with the operating valves being fully opened.
Loop seal clearing phenomenon is predicted with good accuracy in both legs of the loop 1, having a delay of only 5 s compared to the measurement. On the other hand, both the calculation and the experiment do not show loop seal clearing for the intermediate leg $2 \mathrm{~A}$ for the whole test duration while the intermediate leg $2 \mathrm{~B}$ is cleared $1000 \mathrm{~s}$ ealier in the calculation than in the experiment. This phenomenon will be further discussed in the next section. The calculations are terminated at $3000 \mathrm{~s}$ when no eventual variations are observed in the main test variables. During the test period, the low flow rate conditions of the SITs are not reached. 
Table 2. Measured and Calculated Main Sequence of Events for ISP-50

\begin{tabular}{|c|c|c|c|}
\hline Event & Experiment Data (s) & RELAP5/MOD3.3 Calculation (s) & Remarks \\
\hline Break valve open & 0.0 & 0.0 & \\
\hline First MSSV open for SG1 & 24.5 & 28.1 & \\
\hline First MSSV open for SG2 & 24.5 & 28.1 & \\
\hline LPP trip & 25 & 25 & PRZ pressure $(\mathrm{LPP})<10.72 \mathrm{MPa}$ \\
\hline PRZ heater trip & 25 & 25 & $\mathrm{LPP}+0.0 \mathrm{~s}$ \\
\hline RCP trip & 25 & 40 & $\mathrm{LPP}+0.35 \mathrm{~s}$ \\
\hline Turbine isolation & 25 & 25 & $\mathrm{LPP}+0.07 \mathrm{~s}$ \\
\hline Main feed water isolation & 32 & 31 & $\mathrm{LPP}+7.07 \mathrm{~s}$ \\
\hline Core power decay & 32 & 26 & $\mathrm{LPP}+0.35 \mathrm{~s}$ \\
\hline SIP-2 start & 54 & 54 & $\mathrm{LPP}+28.28 \mathrm{~s}$ \\
\hline SIT activation & 468 & 469 & LUDP $<4.03 \mathrm{MPa}$ \\
\hline \multicolumn{4}{|l|}{ Loop seal clearing } \\
\hline CL1A & 189 & 184 & \\
\hline CL1B & 189 & 184 & \\
\hline CL2A & - & - & did not take place \\
\hline CL2B & 1230 & 209 & \\
\hline Low flow rate of SIT & - & - & did not take place \\
\hline Test stop & 2933 & 3000 & \\
\hline
\end{tabular}

\subsection{Transient Results}

Comparison of time trends for important test variables with the experimental data of the ISP-50 is presented in this subsection. The time trend of the break mass flow rate is depicted in Fig. 3 as predicted by the Henry-Fauske chocked flow model. The comparison with the experimental data shows that the trend of the break flow is very well predicted by the calculations. At the opening of the break valve, subcooled water is discharged to the containment vessel for a short period of time showing a high peak in the break mass flow rate which is slightly overpredicted in the calculations. Afterwards, a change to saturated twophase flow regime takes place and it extends for a period of $\sim 200 \mathrm{~s}$. Then, the break mass flow rate decreases with the start of discharging single phase water vapor through the break opening. Moreover, after $1600 \mathrm{~s}$, low liquid void fraction break flow is observed due to entrainment of water droplets from the downcomer. The accumulated break flow calculated by the time integration of the RELAP5 break mass flow rate is compared with the experimental data in Fig. 4. It shows an initial steep increase with a good agreement with the experimental data in the first $200 \mathrm{~s}$ and afterwards a change in the slope is observed with a difference of $120 \mathrm{~kg}$ with the experiment at the end of the test. This is due to the underestimation of the break mass flow rate when it is in the two-phase regime as shown in Fig. 3. The Henry-Fauske model employs only a single discharge coefficient throughout the whole transient for all the discharge flow phases. A discharge coefficient of 0.82 was adopted through sensitivity calculations in order to reproduce as close as possible the primary system pressure. The default value of the non-equilibrium coefficient of 0.14 is used to describe the deviation from equilibrium conditions between the phases. In the same figure, the accumulated ECC water from both the SIP-2 and the three intact SITs is plotted against the measurement. The accumulated ECC is slightly underpredicted at the end of calculations by $\sim 4 \%$ due to underestimation of the ECC flow coming from the SITs. Sensitivity analysis of the k-loss factors in the DVI line does not show differences in the results. On the other hand, very high reverse k-loss coefficients are assumed in order to avoid back flow to the SIT vessels.

The primary and secondary pressure transient trends are shown in Fig. 5. Only the secondary pressure in the steam dome of the steam generator in loop 1 is shown, 


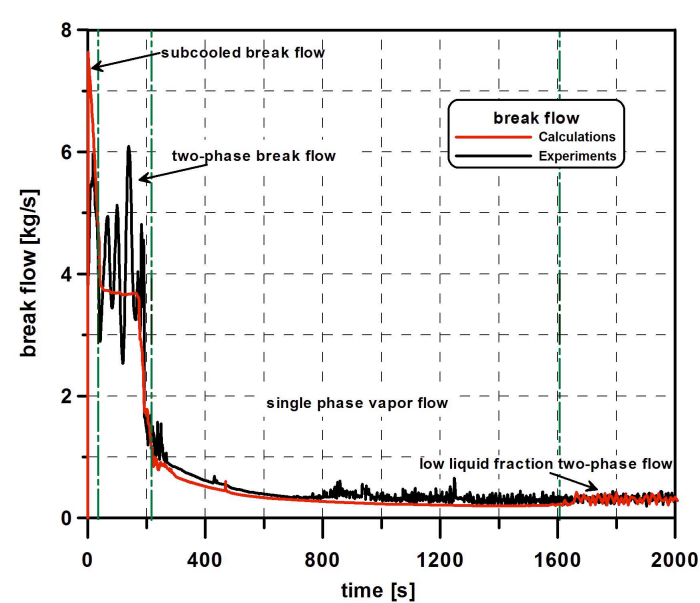

Fig. 3. Time Trend of the Break Mass Flow Rate

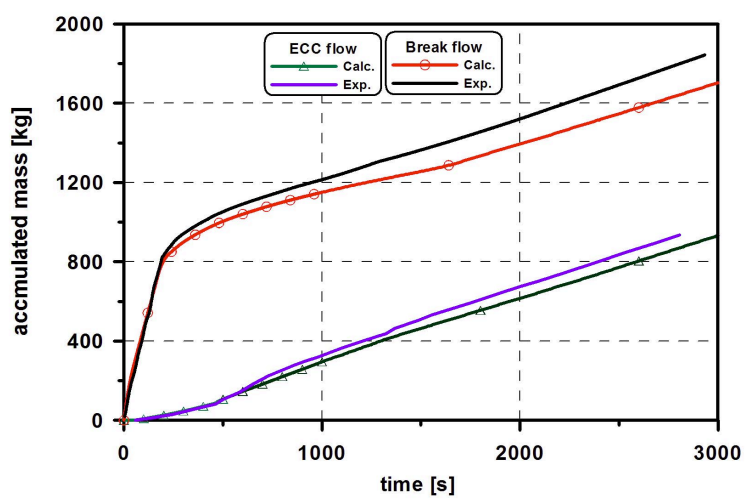

Fig. 4. Break and ECC Accumulated Mass Flow Rate

since both steam generators show quite similar trends. The primary pressure shows very good agreement with the experimental data. Initially, the primary pressure undergoes a fast depressurization due to the abrupt loss of the coolant water inventory in the first $50 \mathrm{~s}$ and then it reaches a plateau value and it becomes nearly equal to the secondary pressure. The plateau region remains for $150 \mathrm{~s}$ and shows some pressure oscillations in response to the oscillation of the secondary pressure when the MSSVs open and close intermittently. Afterwards, it decreases again. An enlarged plot of the plateau region is illustrated in the same figure. It is shown that five MSSVs openings are calculated while only three openings are observed in the experiment. The extra two openings of the MSSVs are taking place between 30 and 50 seconds and this overestimation can be attributed to the overprediction of heat transfer rates between the primary and secondary sides due to overprediction of hot legs flow rates in this time window. The secondary pressure monotonically decreases later on due to the heat losses from the secondary loops to the environment. The heat losses from the primary and both secondary sides added together are plotted in Fig. 6

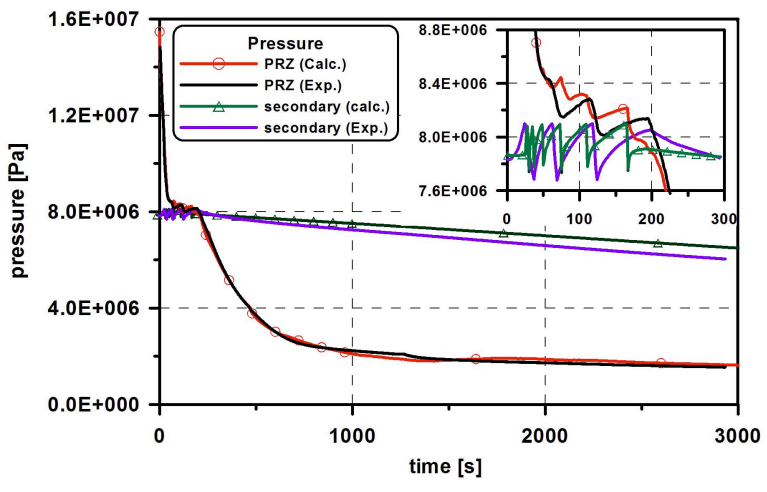

Fig. 5. Pressure Trends in the Primary (Pressurizer) and Secondary Sides

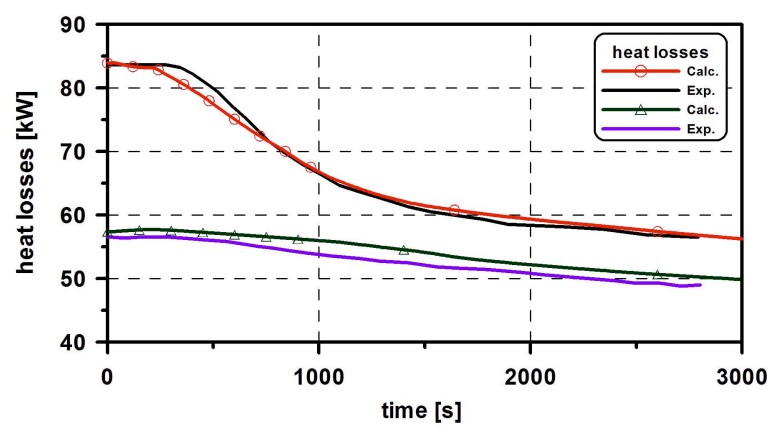

Fig. 6. Heat Losses in the Primary and Secondary Sides

showing close agreement with the experimental data. Initially, they are 84 and $58 \mathrm{~kW}$ from the primary and secondary sides, respectively. When the transient starts, they show a decreasing trend with time due to the temperature decrease of structure materials.

The collapsed water levels in the downcomer annulus and in the RPV core are depicted in Fig. 7. The general trends of the collapsed water levels are well reproduced in the calculations. At the break occurrence, the water level in the core continuously and quickly decreases reaching a minimum value of $1.3 \mathrm{~m}$ which uncovers the reactor core to slightly lower than its mid active height at $170 \mathrm{~s}$, being predicted $15 \mathrm{~s}$ earlier than the experiment. The minimum depression of the core water level is well predicted by the code. When the first loop seal is cleared, the core is refilled again with water to a $2 \mathrm{~m}$ height and it further increases to $2.2 \mathrm{~m}$ with the second loop seal clearing predicted in the calculations at $209 \mathrm{~s}$. Afterwards, the predicted core water level is stabilized at this value for the remaining test period with a slight overprediction of $0.1 \mathrm{~m}$ with respect to the experimental observations.

The collapsed water level in the downcomer annulus decreases after the loop seal clearing and shows larger depletion with a prediction underestimation of $0.5 \mathrm{~m}$. When the level in the downcomer decreases to such low values, the level in the core decreases accordingly following a 


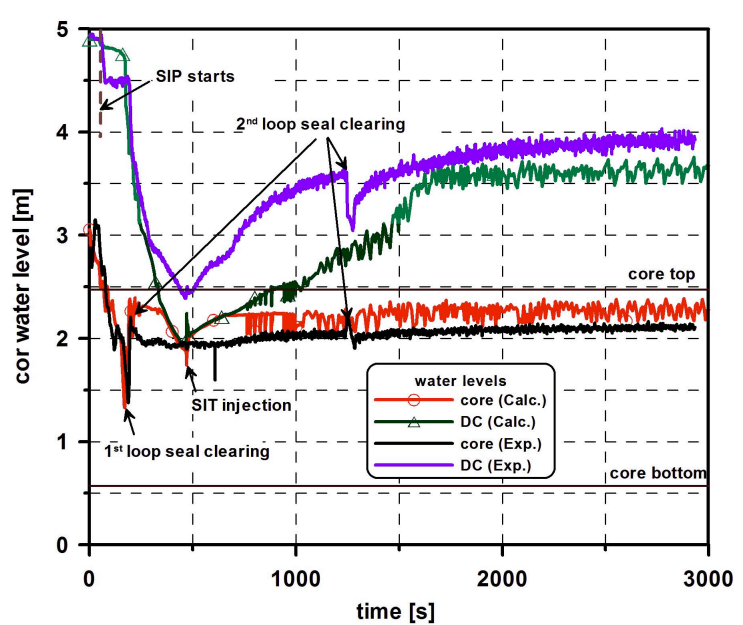

Fig. 7. Collapsed Water Levels in the Core and in the Downcomer

trend very similar to the water level in the downcomer. With the start of the SITs to provide ECC water in the upper annulus of the downcomer at $469 \mathrm{~s}$, the downcomer water level starts to increase again and with the advancement of time it approaches a level close to the experimental data. The underestimation of the downcomer water level, in the time period to $1500 \mathrm{~s}$, leads to the delayed observation of the low liquid void fraction break flow in the last phase of the test compared to the experiment as shown in Fig 3. Using the mixture level track model available in RELAP5, aiming at reducing numerical diffusion errors resulting from the use of the upwind scheme with coarse mesh nodalization and large change in void fractions, did not lead to improvements in the prediction of downcomer water level results. The deficiency can be attributed to the inability of the one-dimensional nodalization to model properly the mixing of the subcooled ECC water with the steam in the upper annulus of the downcomer. In the experimental, the ECC water propagates circumferentially and being mixed efficiently with high rates of interphase heat transfer. Though, cross junctions are used to better simulate three-dimensional effects for the modeling of the downcomer annulus, the collapsed water level in the downcomer is underpredicted due to underprediction of the condensation rate subsequent to mixing in the downcomer.

The calculated and measured Peak Cladding Temperatures (PCT) are plotted in Fig. 8. Both the calculations and the experiment show a small increase in PCT at the time when the core level depression takes place. The occurrence timing and the duration of the temperature peak are predicted in close agreement to the experimental data as shown in the enlarged plot displayed in the same figure. The temperature peak is slightly overpredicted by the calculation by $5 \mathrm{~K}$ due to the slight underestimation of the core level depression before the loop seal clearing.

The loop seal clearing phenomena can be visualized

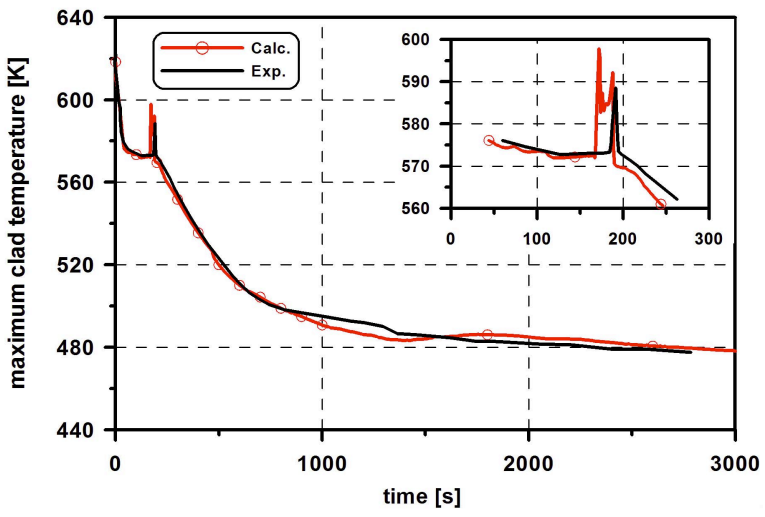

Fig. 8. Trend of the Maximum Clad Temperature

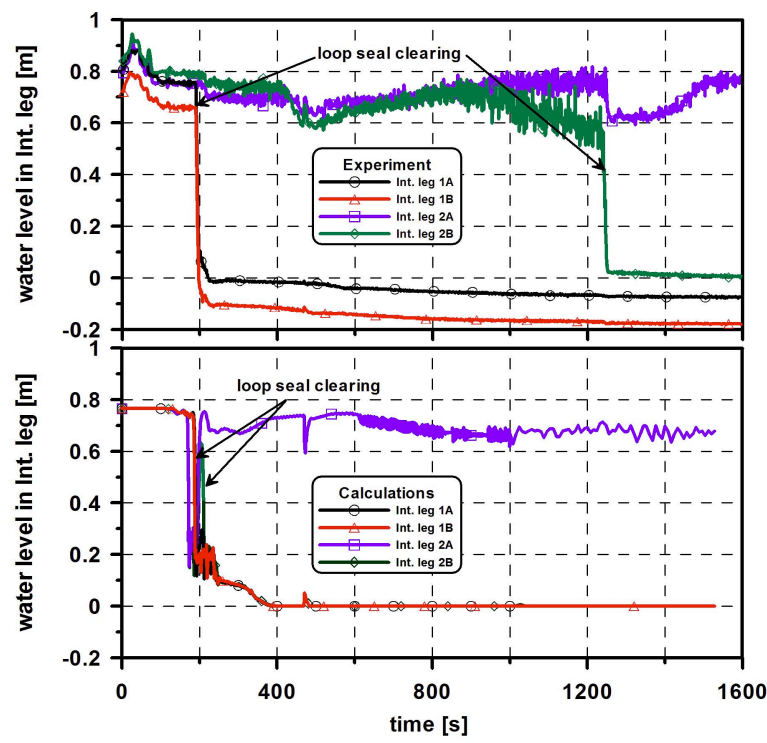

Fig. 9. Collapsed Water Levels in the Intermediate Legs

by plotting the collapsed water level in the vertical section of the intermediate legs. Figure 9 shows the experimental and the calculated loop seal clearing for each of the four intermediate legs. The phenomenon is well predicted in the calculations for the intermediate legs $1 \mathrm{~A}, 1 \mathrm{~B}$ and $2 \mathrm{~A}$; however, for the intermediate leg $2 \mathrm{~B}$ the clearing was much earlier in the calculations than in the experiment. The pressure drops between each hot leg and the cold legs for the two loops are illustrated in Fig. 10 in comparison with the experimental data showing good general trends except for a bias shift for loop 1B. The trends show initial increases in pressure drops due the blockage of the loops by the water in the loop seal. When the pressure in the hot legs reaches considerably high values to overcome the resistance introduced by the sealing in the intermediate legs, the seal is cleared and the pressure differences decrease. The loop pressure drops reach very low values and only increase momentarily in the calculation when the SITs are started. 


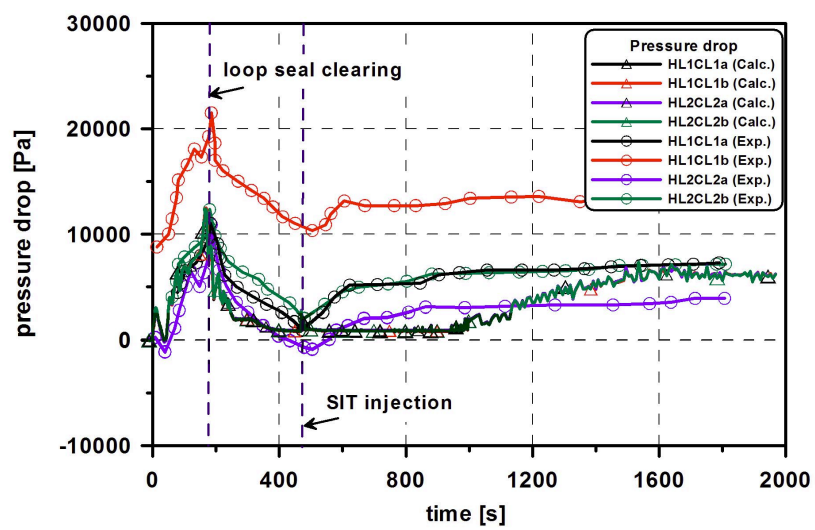

Fig. 10. Pressure Drop Trends Along the Different Loops

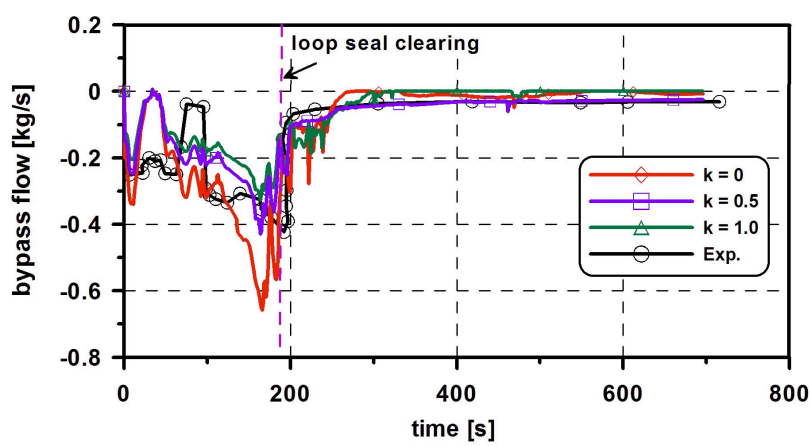

Fig. 11. Bypass Flow from the Downcomer to the Hot Legs

Afterwards, the pressure drops increase at $1000 \mathrm{~s}$ with the refill of the hot legs with the two phase flow coming from the core and the condensate coming from the Utube of the steam generators. The pressure drops in the experiment do not show particular behavior for the delayed loop seal clearing in the second loop. The prediction of earlier timing for the loop seal 2B can be attributed instead to the conditions in the downcomer which are not properly simulated due to the aforementioned reasons.

The bypass flow between the downcomer and the hot legs are also expected to influence the occurrence timing of the loop seal clearance. In Fig. 11, the trend of the bypass flow is shown against the experimental observations. The flow is going in the direction from the hot legs to the downcomer and it increases due to the increase of the pressure difference resulting from blockage of the loop. When the loop seal is cleared, the bypass flow is decreased and it reaches a stable low value. In a sensitivity study, the loss coefficient along the bypass line is increased from 0 to 0.5 and to 1 resulting in a decrease in the bypass flow rate to the downcomer. For each of these cases different timing of seal clearance is predicted as shown in Fig. 12. For the case with $\mathrm{k}=0.5$, no loop seal clearance is observed in both of the intermediate legs of the second loop, however,

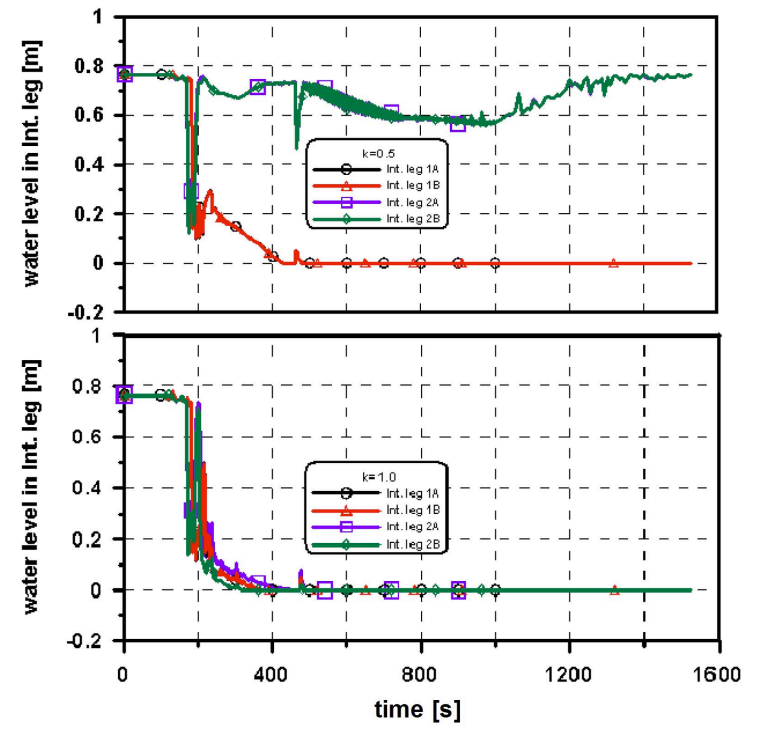

Fig. 12. Effect of the Bypass Flow on the Timing Occurrence of the Loop Seal Clearing

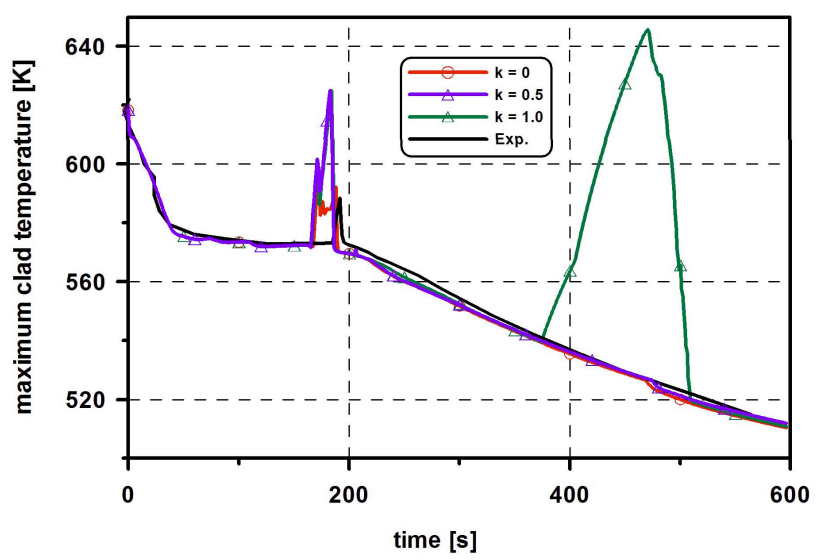

Fig. 13. Effect of the Bypass Flow on the Maximum Clad Temperature

for the case with $\mathrm{k}=1$, the loop seal is cleared in all of the four intermediate legs early in the transient. This shows the sensitivity of the loop seal clearance timing to the water level in the downcomer which suggests that correct prediction of the water level conditions in the downcomer is important to correctly reproduce the timing for the loop seal clearance. Nevertheless, the one-dimensional simulation of the core and downcomer adopted in this work showed the capability of the RELAP5/MOD3.3 code to reproduce the main phenomena occurring during the DVI break transient with a reasonable accuracy.

It is also worth noting that modelling of the bypass flow from the downcomer to the hot leg affects the prediction of the maximum cladding temperature as shown in Fig. 13. 
With the decrease of the bypass flow, the core level achieves lower values (less flow reaches the downcomer) before the loop seal clearance due to the blockage of the loop and therefore higher temperature peaks are observed. A second peak is observed for the case $\mathrm{k}=1$ due to the second depression of the core level which in this case reaches lower values (bypass flow at time $300 \mathrm{~s}$ is close to zero for $\mathrm{k}=1$ as depicted in Fig. 11). This shows the need for accurate modeling of this quite uncertain quantatity.

\section{CONCLUSIONS}

The best-estimate RELAP5/MOD3.3 code was used to simulate the 50\% DVI line break SBLOCA transient scenario in the ATLAS facility. The calculations have been performed in the framework of the ISP-50 making use of the open test data provided by the organizing institution to evaluate the capabilities of the RELAP5/ MOD3.3 code to reproduce the observed thermal-hydraulic phenomena.

Two-dimensional representation of the downcomer annulus using six azimuthal sections connected together with cross junctions was adopted to better simulate multidimensional effects. The Henry-Fauske choked flow model with a discharge coefficient of 0.82 was used in the simulations through sensitivity study to reproduce the pressure transient in the primary system. Comparing the results with the experimental data showed that the overall trends are well reproduced with the adopted models. The primary pressure prediction showed excellent agreement with the experimental data while the secondary pressure was slightly overpredicted, specifically in the early phase of the transient showing two more openings of the MSSVs. The difference was attributed to the high heat transfer rate between the primary and the secondary sides resulting from the slight overestimation of the hot legs flow rates.

The trends of the collapsed water levels are well predicted in the calculations for the core and for the downcomer. In particular the depression of the level in the core before the loop seal clearance and the subsequent core refill is well predicted. In accordance, a small PCT is observed in the experiment and also it was reproduced in the calculations. On the other hands, the downcomer water level was underestimated by about $0.5 \mathrm{~m}$ before the activation of the SIT; however with the advancement of the test time, the predictions approached closely the experimental data. The difference was attributed to multidimensional effects in the downcomer that were not properly taken into account in the model. The timing for different events were accurately predicted except for the second loop seal clearance. Sensitivity analysis on the bypass flow from the downcomer to the hot leg showed dependence of the loop seal clearance timing on the bypass flow. It was concluded that the loop seal clearance timing depends closely on the conditions of the downcomer which are not accurately captured by one-dimensional nodalization.

\section{ACKNOWLEDGEMENTS}

This study was performed in the framework of the ISP-50 organized jointly by NEA/CSNI and KAERI.

\section{REFERENCES}

[1] Korea Hydro \& Nuclear Power Co., "Overview on the Advanced Power Reactor APR1400," http://www.apr1400. com (2006).

[2] Kim Y.S., Choi K.Y., Park H.S., Cho S., Kim B.D., Choi N.H. and Baek W.P., "Commissioning of the ATLAS Thermal-Hydraulic Integral Test Facility," Annals of Nucl. Energy, vol. 35, pp. 1791-1799 (2008).

[ 3 ] Park H.S., Choi K.Y., Cho S., Kang K.H. Choi N.H., Kim Y.S. and Bael W.B., "Major Findings from LBLOCA Reflood Test Using the ATLAS Facility," Nucl. Eng. \& Dsgn., vol. 240, pp. 3920-3929 (2010).

[4] Kang K.H., Park H.S., Cho S., Choi N.H., Bae S.W., Lee S.W., Kim Y.S., Choi K.Y., Bae W.P. and Kim M.Y., "Experimental Study on Blowdown Load during the Steam Generator Feedwater Line Break Accident in the Evolutionary Pressurized Water Reactor," Annals of Nucl. Energy, vol. 38, pp. 953-963 (2011).

[ 5 ] Yun B.J., Son C.H., Min K.H. and Park G.C., "Experimental Observations of the Hydraulic Phenomena in the APR1400 Downcomer during the DVI Line Break Accident," Korea Nuclear Society Spring Meeting, KNS, Daejeon (2003).

[6] Lee K.H., Bae B.U., Kim Y.S., Yun B.J., Chun J.H. and Park G.C., "An Integral Test and MARS Code Analysis for a DVI Line Break LOCA,” Nucl. Eng. \& Dsgn., vol. 238, pp. 3336-3347 (2008).

[ 7 ] Choi K.Y., Park H.S., Cho S., Kang K.H., Choi N.H., Baek W.P., Kim Y.S., "Effects of Break Size on Direct Vessel Injection Line Break Accidents of the ATLAS," Nucl. Technology, V. 175, pp. 604-618 (2011).

[ 8 ] KAERI, "ISP-50 Specifications for a Direct Vessel Injection Line Break Test with the ATLAS," KAERI/TR-3778/ 2009, Daejeon (2009).

[9] Nuclear Regulatory Commission, "RELAP5/MOD3.3 Code Manuals," The Thermal Hydraulics Group, Idaho (1999).

[10] Ishii M. and Kataoka I. "Similarity Analysis and Scaling Criteria for LWRs Under Single Phase and Two-Phase Natural Circulation," NUREG/CR-3267, ANL-83-32, ANL, USA (1983).

[11] ANS, "Decay Heat Power in Light Water Reactor," American Nuclear Society, ANSI/ANS 5.1, LaGrange Park, IL, USA (1979).

[12] Henry R.E. and Fauske H.K. "The Two-Phase Critical Flow of One-Component Mixtures in Nozzles, Orifices, and Short Tubes," J. Heat Transfer, vol. 179 (1971). 